\title{
Class-based storage location assignment - an overview of the literature
}

\author{
, Behnam Bahrami* Hemen Piri, and El-Houssaine Aghezzaf \\ Department of Industrial Systems Engineering and Product Design, Ghent University, Belgium \\ *Behnam.Bahrami@UGent.be
}

Keywords: Warehouse operations, class-based storage location assignment problem, literature review.

\begin{abstract}
Storage, per se, is not only an important process in a warehouse, also it has the greatest influence on the most expensive one, i.e., order picking. This study aims to give a literature overview on class-based storage location assignment (CBSLAP). In this paper, we discuss storage policies and present a classification of storage location assignment problem. Next, different configuration of classes are presented. We identify the research gaps in the literature and conclude with promising future research directions.
\end{abstract}

\section{INTRODUCTION}

Establishment of effective and smooth logistics operations is under pressure by the growing trend of shorter time window order fulfillment, bigger product assortment and smaller order quantities. Contributing to a large share of the total product costs, logistics operations are determinants in company's survival in the current competitive business world. The efficiency and effectiveness of a distribution network, in turn, greatly depends on the performance of the nodes in such a network, i.e., the warehouses (Rouwenhorst et al, 2000). Warehouse operations are thus crucial in the context of logistics. They provide a means to make the storage of all kind of inventories, from raw material to final products, easier among upstream to downstream stages of a supply chain (Choy et al, 2017). Planning the warehouse operations in an effective way is not simple because they consist of different activities (Lam et al, 2015). These operations can be categorized into four activities or processes: receiving, storage, orderpicking and shipping ((van den Berg and Zijm, 1999); (Gu et al, 2007); (Rouwenhorst et al, 2000)).

The interface of a warehouse for incoming and outgoing material flow are receiving and shipping. Storage deals with assignment of products to storage locations to utilize space as much as possible and facilitate efficient material handling ( $\mathrm{Gu}$ et al, 2007). Order picking is the retrieval of items from their storage locations and can be performed manually or (partly) automated (Rouwenhorst et al, 2000).
Storage is traditionally considered as the most important facet of logistics. Efficient inventory control, lower personnel cost, higher productivity, and convenient product identification are the outcomes of a proper storage system (Fontana and Cavalcante, 2014). Order fulfillment time, and thereby customer service level, can substantially be improved by even slight storage process enhancements (Fontana and Nepomuceno, 2017).

The amount of stored products, the time and the rate of reorders, and the place of inventories in the warehouse are three basic and main issues that should be addressed in storage function ( $\mathrm{Gu}$ et al, 2007). Classical inventory control fields of lot sizing and staggering deal with the first two topics that are out of the scope of this paper.

The storage location assignment problem (SLAP) deals with how to put the stock keeping units (SKUs) away in a warehouse to optimize a performance measure (Kovács, 2011). Customers ask for more diverse products which cause warehouses to take on larger product assortment and this situation accordingly leads to a more complex storage location assignment problem (Choy et al, 2017). Storage location assignment influences almost all key warehouse performance indicators including orderpicking time and cost, productivity, shipping and inventory accuracy, and storage density (Frazelle, 2002). The most important performance measures in a warehouse are generally related to the time or effort required for order picking (Kovács, 2011). Picking performance is directly affected by storage process 
and, therefore, it is tried to consider this interaction in the design stage (Davarzani and Norman, 2015). Roodbergen and de Koster (2001) have presented four approaches to reduce travel time or distance for order picking activity: (1) determining good order picking routes; (2) zoning the warehouse; (3) assigning products to the right storage locations; (4) picking orders in batches. The third approach, storage assignment of SKUs, is more influential on the effectiveness of order picking than any of the other three approaches and a well-designed storage assignment approach could substantially decrease the travel distance or time of order picking (Chiang et al, 2014). Higher material handling costs and lower space utilization are the outcomes of unsystematic assignment of SKUs to storage locations (Choy et al, 2017).

In the next section, we introduce, classify and discuss different storage policies and various existing methodologies of CBSLAP in the literature are presented. Section 3 is about configuration of classes and finally we conclude the paper with presenting the identified research gaps and future research directions..

\section{STORAGE POLICIES}

Products can be assigned to storage locations either arbitrarily or based on certain criteria. The first option is often referred to as "random policy"; we will refer to it as the "haphazard policy". The second option is referred to as "dedicated storage". Haphazard storage assigns SKUs to locations chaotically over planning horizon while with the dedicated storage the location are kept for specific products in a warehouse. These two policies are the extremes of a spectrum of policies (Malmborg, 1998). In between of these extreme policies of haphazard and dedicated storage, is class-based storage policy. Conversely, haphazard and dedicated storage can be seen as extreme cases of the class-based storage policy: haphazard storage considers a single class and dedicated storage considers one class for each product.

As a general comparison, dedicated storage locates compact and high-demanded items near the input/output (I/O) point, thus is more material handling friendly in comparison to haphazard policy. On the other hand, it needs more storage space to accommodate the maximum inventory levels of each product in their predetermined locations. Class-based storage is a compromised policy that tries to combine the advantages of both policies (Gu et al, 2007). A detailed explanation of each policy will follow.
Since haphazard and class-based policy permit different SKUs to be put away in the same location successively, they are also called shared storage policies, (see figure 1) ((van den Berg and Zijm, 1999); (Kulturel et al, 1999)).

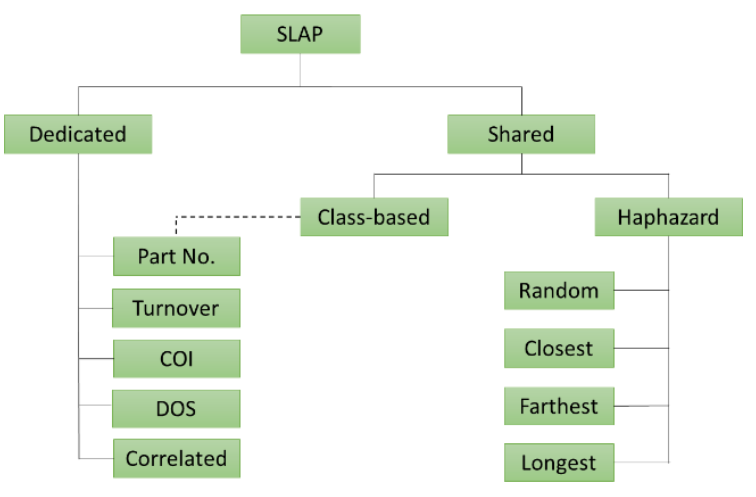

Figure 1: Classification of storage policies

\subsection{Haphazard Storage}

The haphazard policy is a simple procedure and the only information that is needed to implement this policy is if the storage locations are available or not. The most common haphazard policies consist of random location assignment, closest open location, farthest open location and longest open location, (see figure 1), (Gu et al, 2007).

In random assignment, the SKUs are assigned to empty location considering probability. If the replenishers put away the SKUs however they are convenient, the result is probably the so called closest open location storage. They normally put the items in the first vacant locations they come across, which eventually leads to a warehouse with full locations close to I/O point and more spots farther away (de Koster et al, 2007). Hausman et al (1976) explain if the SKUs are transported in full pallets, closest open location storage and random storage result in the same performance. Farthest open location policy allocates the most remote free positions from the I/O point to SKUs. If the locations are assigned to SKUs based on the time they have not been occupied, then it is the longest open location policy.

Haphazard storage is a popular policy in practice due to its simplicity and advantages including space utilization, simple implementation, immunity to demand and assortment fluctuations, and uniform usage of aisles that leads to lower congestion. However, since SKUs do not have predetermined locations a tracking system is required that may cause difficult and confusing positioning. Moreover, in this class of policies, the lack of a systemic view eventually declines the global warehouse 
performance because of not considering consecutive processes and not utilizing product information ((Chiang et al, 2011); (Quintanilla et al, 2015)).

\subsection{Dedicated Storage}

In dedicated storage polices a storage location is allocated and reserved for SKUs over the planning horizon. This allocation is based on a suitable criterion. Kallina and Lynn (1976) present four major determinants for this: compatibility, complementarity, popularity and space. Compatible items can be kept nearby one another without taking risk of contamination, infection, corrosion, or other damages, and hence incompatible items should not be stored closely. Complementary refers to those products that are often concurrently ordered together and it may be beneficial to keep them in adjacent locations. Popular items are those that have a higher demand and if they are stored in locations closer to I/O point, the total travelled distance reduces since popular items are the greatest contributor to this distance. Finally, it is better to allocate the locations near I/O point to the less bulky items.

The most common criteria in the literature, which have also been illustrated in figure 1, are explained as follows.

\subsubsection{Part number}

Assigning SKUs based on their part number is probably the earliest storage policy. Some researchers (e.g. (Brynzér and Johansson, 1996); (Fontana and Nepomuceno, 2017)) have already mentioned part number as a criterion for dedicated policy. Back in the years, without having an information system to track the items, dedicated storage based on the part numbers was helping the storekeepers to find the position of the SKUs by following the sequence of the part numbers. Afterwards, when IT solutions became widespread, cheap and accessible, the application of part number as a criterion for dedicated policy became obsolete and old-fashioned.

\subsubsection{Turnover}

One of the most popular criterion for dedicated storage assignment is based on the turnover or demand of the products. With this criterion, the most desired products are placed to the most accessible locations which are usually the ones close to I/O point. Remote locations are assigned to slow-movers (de Koster et al, 2007). One of the problem with this policy is that product turnover rate and the warehouse product portfolio always fluctuate causing violating turnover-based assignment of locations that eventually demands relocations of SKUs to keep the assignment principle and its advantages (Roodbergen and Vis, 2009). In the literature, the turnover-based storage (also known as full-turnover or volumebased) often represents the dedicated policy

\subsubsection{Cube-per-order}

One of the first dedicated storage algorithm is the cube-per-order index (COI) which was proposed by Heskett (1963). The COI is defined as the ratio of maximum allotted space to the number of storage/retrieval operations per unit time. The algorithm places the products with lower COI to more convenient locations and as COI increases the SKUs are located in more distant spots farther from I/O point (Cormier and Gunn, 1992). Although the COI algorithm was initially conceived as a heuristic, several authors later showed that it yields an optimal solution in certain specific environments.

It is worth to mention when single-command, i.e. either a single storage or a single retrieval in each cycle happens, is prevalent, then COI is an excellent candidate. However, Schuur (2015) shows that there is no performance guarantee when a single-command storage strategy is implemented for a multi-command situation, that is, storage and picking of several loads in one cycle. In particular, the worst-case behavior of the COI strategy is infinitely bad.

\subsubsection{Duration-of-stay}

Even though it was first introduced by Goetschalckx and Ratliff (1990) as a shared storage policy, we classify Duration of Stay (DOS) policy as a dedicated one, because based on our definition it is a criterion which an items is assigned to a location. With this policy, in a system where the input and output rate are equivalent, products units, upon their arrivals, get a better location if they stay shorter in the warehouse. In other words, the shorter the DOS of units of products, the closer the location to the I/O point they are placed. The information of incoming/outgoing of all units of a specific must be available to apply DOS procedure while the only required information for turnover policy is the turnover rate at product level (Pohl et al, 2011). This is a crucial consideration as DOS approach needs the most data in comparison to other policies for storage location assignment (Goetschalckx and Ratliff, 1990). Kulturel et al (1999) simulated the performance of turnover-based and DOS-based storage and it turned out that the former had better performance where the reasons may stem from the 
barely existing assumptions of the DOS model in real situations which are more like a pure fantasy in warehouse contexts ((Gu et al, 2007); (Goetschalckx and Ratliff, 1990)).

\subsubsection{Correlation}

Correlated storage (or family-grouping) considers products complementary where stores similar products close to each other in the warehouse. This strategy requires a suitable index to determine, or at least estimate, the correlation among items of the warehouse assortment. The lack of accurate data to calculate this index confines correlated storage application. Dependent demands of different products are easily recognized by the bill of material (BOM) in production environments. However, these interrelations are more complex to utilize in distribution warehouses. These changing and hard to predict relationships emanate partially from clients purchase preferences and patterns which can be derived from different resources such as catalogs, promotional plans, market surveys and similar information (Sadiq et al, 1996). Recently the advances in the field of big data, data analytics and data mining facilitate identification of correlated products.

Dedicated storage policies have the lowest space utilization in comparison to other policies for this they allot space for all items such that to be able to accommodate the maximum level of inventory while most of the time the inventories are not at their maximum level and even stock-outs may happen (de Koster et al, 2007).

In addition, contrary to haphazard policies which utilize the picking aisles evenly, the picking activities in the COI-based and turnover-based storage policies concentrate on the regions where items with low COI and high turnover are located. For one order picker system, clearly congestion is not an issue. This is also true for small warehouses as well as large warehouses divided into zones with one order picker in each zone (Caron and Perego, 1998). However, in those environments where several order pickers work simultaneously the situation is different and more pickers does not essentially leads to higher throughput. This issue is more severe in storage systems where turnover-based approach implemented, that is, the more the number of workers the higher the productivity reduction. This is a main incapability in this class of storage policies which is more troublesome where demand seasonality is present as well (Ruben and Jacobs, 1999).

Finally, although dedicated storage yields the minimum travel time, it is not practically popular as its implementation is not simple thus is used as a performance benchmark to evaluate other storage policies. Even some authors (e.g., (Rosenblatt and Eynan, 1989)) view its implementation as "practically impossible". A reason is that abundant information is a prerequisite for a high performance from the policy. Accurate data, continuous supervision and capability to cope with ceaseless changes are requirements of a successful dedicated storage which are all difficult to gain and accomplish in many warehouses ((Tompkins et al, 2010); (Rao and Adil, 2013)).

\subsection{Class-based Storage}

Class-based storage is a compromised policy that classifies SKUs into product classes, based on an appropriate criteria such as volume or usage rate. The SLAP now is the problem of assignment of SKUs to a product class and then a class to a storage region in the warehouse. Items are positioned in their class following a simple haphazard rule, e.g. random or nearest open location. Haphazard policy is actually the class-based policy with one class and if each product has its own class, then it is dedicated policy (Gu et al, 2007). Class-based storage with three classes often is referred to as ABC storage (Roodbergen and de Koster, 2009). Class-based storage is popular among practitioners due to its great capabilities such as simple implementation, manageable maintenance and ability to cope with product mix and demand variations (Le-Duc and de Koster, 2005). No need for full sorted list of SKUs and more convenient administration are the reasons of easier implementation of class-based storage in comparison to dedicated storage. Class-based storage also outperforms haphazard storage in terms of travel time that is comparable to that of dedicated storage as well (Petersen and Aase, 2004).

The general belief, among the warehouse community, is that dedicated storage yields lower travel distances than class-based storage. Petersen and Aase(2004) demonstrate that a turnover-based dedicated policy performs better than class-based policy with three classes but this improvement is less than $1 \%$ that even this may not be true because haphazard allocation of SKUs in the classes causes lower storage area and consequently shorter order picking time (Muppani and Adil , 2008a). Travel time of class-based policy, in traditional research, is considered at its best to approach to that of turnoverbased policy. However, Guo and de Koster (2015) show that the average one way travel distance of the turnover-based storage is not a lower bound in the warehouse. Space sharing is the answer of this contradiction; since SKUs share the warehouse space in haphazard storage hence less space is required (almost two third) in comparison with turnover-based 
policy that subsequently influences the average travel time. Furthermore, Muppani and Adil (2008b) observed that where a system suffers from high inventory fluctuations of SKUs, class-based solutions perform better than dedicated approach.

The strength of class-based policy is in taking advantage of the logic of dedicated storage, while avoiding the exhaustive chores alongside (Petersen and Aase, 2004). For this, Class-based policy classify products based on some criteria, and once all products have their class being determined, neglect the criteria for the period of planning horizon to exploit the simplicity and convenience of haphazard storage policy. Most previous studies used turnover rate as the basis to classify products for storage assignment (Chiang et al, 2014) but all other criteria which were explained for dedicated storage may be applied for this purpose. This is the reason why these criteria have been connected to the class-based box with a dashed line in figure 1.

\section{Configuration of Classes}

The performance of a warehouse is highly affected by its layout (configuration), the way SKUs are placed in and picked from locations and also the position of I/O points. Several authors studied configuration of classes in a warehouse. A surprising result in this field is that the optimal configuration for a warehouse with a specific capacity is independent of the storage policy. This fact makes the design of storage system easier since the designers do not have to worry about which policy is or will be put into practice. They just need to optimize the configuration considering a simple (e.g. haphazard) policy, whatever the result is, the storage shape is optimal for other policies such as turnover-based or class-based storage (Zaerpour et al 2013)

\subsection{Class formation}

Rosenblatt and Eynan (1989) developed a onedimensional search procedure to determine optimal boundaries for class-based policy. They show that using a relatively small number of classes can result ,in average, travel times which approach travel times obtained for the turnover-based assignment. Some authors have already suggested some numbers for class formation. For instance, Rao and Adil (2013) claim that maximum of three classes is sufficient to get a major extent of the benefit of turnover policies and Guo and de Koster (2015) argue a class-based policy with a small number of classes, no more than 5 , is optimal.

Although conventional research (e.g., (Eynan and Rosenblatt, 1994), (Rosenblatt and Eynan, 1989)) show that there is inverse relation between picking time and the number of classes (figure 2), warehouse managers limit the number of classes to a small number. Yu et al (2015) demonstrate that the travel

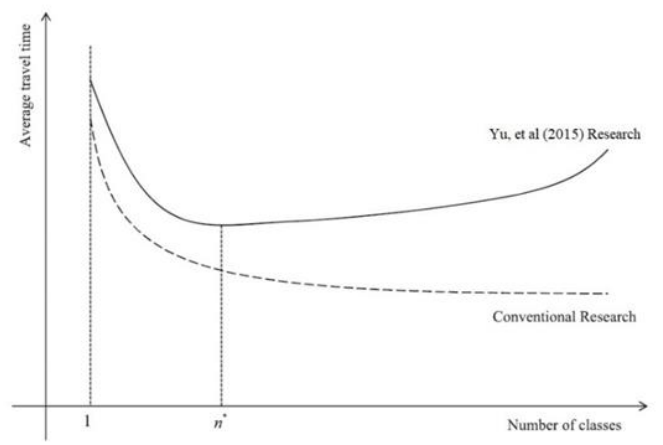

Figure 2: Inverse relation between picking time and the number of classes (Yu et al, 2015)

time function has a different shape (figure 2) and, contrary to previous studies, there is an optimum for the number of classes. Another main result of their study is the insensitivity of travel time function to the number of classes in a wide range around the optimal number of classes which is something between 3 to 8 . This is a good news for the warehouse managers since this gives them more freedom in implementing classbased policy and they can also take into account their practical constraints.

\subsection{Implementation of classes}

Hausman et al (1976) consider the problem of finding class regions for the class-based storage policy. The authors suggest L-shaped (figure 3(a)) class regions. This shape is optimal for Chebyshev travel times, if only single-command cycles are present. They analytically determine optimal class sizes for two classes in a square-in-time rack, such that the mean single-command travel time is minimized. Graves et al (1977) observe that L-shaped regions are not necessarily optimal when dualcommands occur. Petersen and Schmenner (1999) present four variations for turnover-based storage: diagonal, within-aisle, across-aisle, and perimeter storage which can also be considered as different variations for class-based policy, (figure 3(b)-(e)) They show within-aisle storage with a middle I/O point is the best storage policy for all pick lists. The middle I/O point is better than the corner I/O point. However, this difference becomes almost nonexistent for large pick lists.

The within-aisle strategy has also later been shown to have a higher performance than other storage implementation strategies regardless of the 


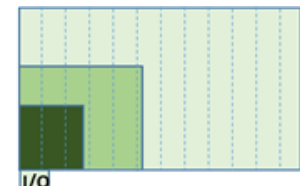

(a) L-shaped

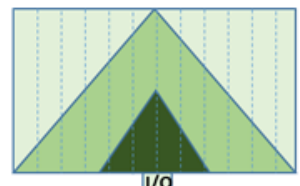

(b) Diagonal

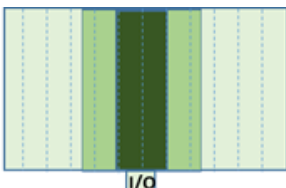

(c) Within-aisle

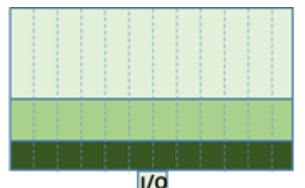

(d) Across-aisle

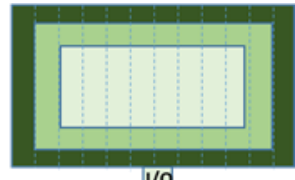

(e) Perimete

Figure 3: Implementation of classes

number of storage classes. ((Petersen et al, 2004); (van Gils et al, 2017)).

\section{CONCLUSION AND FUTUREESEARCH DIRECTIONS}

This paper draws a framework for the class-based storage location assignment problem in the warehouse storage process. According to the examined studies, a number of conclusions are addressed.

First of all, we would like to draw the attention of researchers to integrated warehouse operations. The importance of integrated warehouse problems has already been highlighted by some other authors (e.g., (Roodbergen and Vis, 2009); (Cergibozan and Tasan, 2016); (van Gils et al, 2017)). However, the focus of the research community has been on combination of the storage, batching and routing. The significant statistical correlation of storage, batching and routing has already been tested and confirmed.

Second, the potential advantage of integrated models is clear but they have not still been validated in complex industrial contexts. This gap is not only limited to integrated models but also incorporate studies which just deal with SLAP in its own. The few published industrial case studies ((van Oudheusden et al, 1988); (Zeng et al, 2002); (Dekker et al, 2004)) accentuate the lack of balance between papers with an assumption-restricted modeling approach and those based on the complex reality of warehouses. This gap has been also underscored by other studies ( $(\mathrm{Gu}$ et al, 2007); (Davarzani and Norman, 2015)) in warehouse literature and it shows the limited cross fertilization between research community and practitioners. A good liaison establishment between academia and industry is a win-win situation. On the one hand, it helps researchers in better understanding the reality to identify possible future research challenges from the industrial point of view. On the other hand, research results with a validity check on real-case environments will have a more substantial impact on practice. Therefore, practical case studies and research, explaining applied or validated methodologies which illustrate the potential advantages of implementing scientific literature results to real problems, or on discovering the unknown challenges which hinder their successful implementation is another direction for future contribution.

Some researchers introduced other measures for SLAP along with economics measures. Future research should focus on other performance measures as well. For instance, an important subject in progress is the sustainability issues in logistics. Sustainable operations have been widely studied in past years, but the inclusion of metrics in warehouse management have still place for examination (Staudt et al, 2015). Although energy efficiency and environmental performance have gained increasing attention during past couple of decades in operations management literature, majority of the reviewed literature focused on economic efficiency of SLAP. Social awareness and governmental regulations about global warming and environmental issues spotlight this topic. Another instance is the inclusion of human factors into SLAP models. Reminding that majority of operating warehouses are still manual systems, put more emphasize on the importance of further research in this field.

Finally, the early focus of warehouse management research was on process improvement which essentially does not need IT tools. However, the complexity of warehouse operations has increased in recent years and more complicated algorithm and models appear in warehouse management publications (Staudt et al, 2015). Application of information systems in warehouse management is a growing tendency and the related new technologies will certainly be used for decision making in the future. We believe there is big room to study opportunities and challenges of employing more advanced technologies and initiatives such as augmented reality, internet of things, cloud technologies, cyber physical systems and Industry 4.0 not only in SLAP but also in other warehouse processes in general.

\section{REFERENCES}

Ang, M., Y.F. Lim, and M. Sim, Robust Storage Assignment in Unit-Load Warehouses. Management Science, 2012. 58(11): p. 2114-2130. 
Brynzér, H. and M.I. Johansson, Storage location assignment: Using the product structure to reduce order picking times. International Journal of Production Economics, 1996. 46(Supplement C): p. 595-603.

Caron, F., G. Marchet, and A. Perego, Routing policies and COI-based storage policies in picker-to-part systems. International Journal of Production Research, 1998. 36(3): p. 713-732.

Cergibozan, Ç. and A.S. Tasan, Order batching operations: an overview of classification, solution techniques, and future research. Journal of Intelligent Manufacturing, 2016.

Chiang, D.M.-H., C.-P. Lin, and M.-C. Chen, The adaptive approach for storage assignment by mining data of warehouse management system for distribution centres. Enterprise Information Systems, 2011. 5(2): p. 219234.

Chiang, M.-H.D., C.-P. Lin, and M.-C. Chen, Data mining based storage assignment heuristics for travel distance reduction. Expert Systems, 2014. 31(1): p. 81-90.

Choy, K.L., G.T.S. Ho, and C.K.H. Lee, A RFID-based storage assignment system for enhancing the efficiency of order picking. Journal of Intelligent Manufacturing, 2017. 28(1): p. 111-129.

Cormier, G. and E.A. Gunn, A review of warehouse models. European Journal of Operational Research, 1992. 58(1): p. 3-13.

Davarzani, H. and A. Norrman, Toward a relevant agenda for warehousing research: literature review and practitioners' input. Logistics Research, 2015. 8(1)

Dekker, R., et al., Improving Order-Picking Response Time at Ankor's Warehouse. Interfaces, 2004. 34(4): p. 303313.

de Koster, R., T. Le-Duc, and K.J. Roodbergen, Design and control of warehouse order picking: A literature review. European Journal of Operational Research, 2007. 182(2): p. 481-501.

Eynan, A. and M.J. Rosenblatt, Establishing zones in single-command class-based rectangular AS/RS. IIE Transactions, 1994. 26(1): p. 38-46.

Fontana, M.E. and C.A.V. Cavalcante, Use of Promethee method to determine the best alternative for warehouse storage location assignment. The International Journal of Advanced Manufacturing Technology, 2014. 70(9): p. 1615-1624.

Fontana, M.E. and V.S. Nepomuceno, Multi-criteria approach for products classification and their storage location assignment. The International Journal of Advanced Manufacturing Technology, 2017. 88(9): p. 3205-3216.

Frazelle, E., World-class Warehousing and Material Handling. 2002: McGraw-Hill.

Goetschalckx, M. and H.D. Ratliff, Shared Storage Policies Based on the Duration Stay of Unit Loads. Management Science, 1990. 36(9): p. 1120-1132.

Graves, S.C., W.H. Hausman, and L.B. Schwarz, StorageRetrieval Interleaving in Automatic Warehousing Systems. Management Science, 1977. 23(9): p. 935945.
Gu, J., M. Goetschalckx, and L.F. McGinnis, Research on warehouse operation: A comprehensive review. European Journal of Operational Research, 2007. 177(1): p. 1-21.

Guo, X., Y. Yu, and R.B.M. De Koster, Impact of required storage space on storage policy performance in a unitload warehouse. International Journal of Production Research, 2015. 54(8): p. 2405-2418.

Hausman, W.H., L.B. Schwarz, and S.C. Graves, Optimal Storage Assignment in Automatic Warehousing Systems. Management Science, 1976. 22(6): p. 629638.

Heskett, J.L., Cube-per-order index-a key to warehouse stock location. Transportation and distribution Management, 1963. 3 (1): p. 27-31.

Kallina, C. and J. Lynn, Application of the Cube-Per-Order Index Rule for Stock Location in a Distribution Warehouse. Interfaces, 1976. 7(1): p. 37-46.

Kovács, A., Optimizing the storage assignment in a warehouse served by milkrun logistics. International Journal of Production Economics, 2011. 133(1): p. 312318.

Kulturel, S., et al., Experimental investigation of shared storage assignment policies in automated storage/retrieval systems. IIE Transactions, 1999. 31(8): p. 739-749

Lam, H.Y., et al., A knowledge-based logistics operations planning system for mitigating risk in warehouse order fulfillment. International Journal of Production Economics, 2015. 170: p. 763-779.

Le-Duc , T. and R.B.M. De Koster, Travel distance estimation and storage zone optimization in a 2-block class-based storage strategy warehouse. International Journal of Production Research, 2005. 43(17): p. 35613581 .

Malmborg, C.J., Analysis of storage assignment policies in less than unit load warehousing systems. International Journal of Production Research, 1998. 36(12): p. 34593475.

Muppani, V.R. and G.K. Adil (a), Class-based storagelocation assignment to minimise pick travel distance. International Journal of Logistics Research and Applications, 2008. 11(4): p. 247-265.

Muppani, V.R. and G.K. Adil (b), Efficient formation of storage classes for warehouse storage location assignment: A simulated annealing approach. Omega, 2008. 36(4): p. 609-618.

Petersen, C.G. and R.W. Schmenner, An Evaluation of Routing and Volume-based Storage Policies in an Order Picking Operation. Decision Sciences, 1999. 30(2): p. 481-501.

Petersen, C.G. and G.R. Aase, A comparison of picking, storage, and routing policies in manual order picking. International Journal of Production Economics, 2004. 92(1): p. 11-19.

Petersen, C., C. Siu, and R.D. Heiser, Improving order picking performance utilizing slotting and golden zone storage. International Journal of Operations \& Production Management, 2005. 25(10): p. 997-1012. 
Petersen, C.G. and G.R. Aase, A comparison of picking, storage, and routing policies in manual order picking. International Journal of Production Economics, 2004. 92(1): p. 11-19.

Pohl, L.M., R.D. Meller, and K.R. Gue, Turnover-based storage in non-traditional unit-load warehouse designs. IIE Transactions, 2011. 43(10): p. 703-720.

Rao, S.S. and G.K. Adil, Class-based storage with exact Sshaped traversal routeing in low-level picker-to-part systems. International Journal of Production Research, 2013. 51(16): p. 4979-4996.

Rao, S.S. and G.K. Adil, Analytical models for a new turnover-based hybrid storage policy in unit-load warehouses. International Journal of Production Research, 2016. 55(2): p. 327-346.

Roodbergen, K.J. and R. de Koster, Routing order pickers in a warehouse with a middle aisle. European Journal of Operational Research, 2001. 133(1): p. 32-43.

Roodbergen, K.J. and I.F.A. Vis, A survey of literature on automated storage and retrieval systems. European Journal of Operational Research, 2009. 194(2): p. 343362.

Rosenblatt, M.J. and A. Eynan, Note-Deriving the Optimal Boundaries for Class-Based Automatic Storage/Retrieval Systems. Management Science, 1989. 35(12): p. 1519-1524.

Rouwenhorst, B., et al., Warehouse design and control: Framework and literature review. European Journal of Operational Research, 2000. 122(3): p. 515-533.

Ruben, R.A. and F.R. Jacobs, Batch Construction Heuristics and Storage Assignment Strategies for Walk/Ride and Pick Systems. Management Science, 1999. 45(4): p. 575-596.

Sadiq, M., T.L. Landers, and G. Don Taylor, An Assignment Algorithm for Dynamic Picking Systems. IIE Transactions, 1996. 28(8): p. 607-616.Schuur, P.C., The worst-case performance of the Cube per Order Index slotting strategy is infinitely bad - A technical note. International Journal of Production Economics, 2015. 170: p. 801-804.

Staudt, F.H., et al., Warehouse performance measurement: a literature review. International Journal of Production Research, 2015. 53(18): p. 5524-5544.

Tompkins, J.A., et al., Facilities Planning. 2010: Wiley.

Quintanilla, S., et al., Heuristic algorithms for a storage location assignment problem in a chaotic warehouse. Engineering Optimization, 2015. 47(10): p. 1405-1422.

van den Berg, J.P. and W.H.M. Zijm, Models for warehouse management: Classification and examples. International Journal of Production Economics, 1999. 59(1): p. 519-528.

van Gils, T., et al., Designing efficient order picking systems by combining planning problems: State-of-theart classification and review. European Journal of Operational Research, 2017.

van Oudheusden, D.L., Y.-J.J. Tzen, and H.-T. Ko, Improving storage and order picking in a person-onboard as/r system: A case study. Engineering Costs and Production Economics, 1988. 13(4): p. 273-283.
Yu, Y., R.B.M. de Koster, and X. Guo, Class-Based Storage with a Finite Number of Items: Using More Classes is not Always Better. Production and Operations Management, 2015. 24(8): p. 1235-1247.

Zaerpour, N., R.B.M. de Koster, and Y. Yu, Storage policies and optimal shape of a storage system. International Journal of Production Research, 2013. 51(23-24): p. 6891-6899.

Zeng, A.Z., M. Mahan, and N. Fluet, Designing an efficient warehouse layout to facilitate the order-filling process: An industrial distributor's experience. Production \& Inventory Management Journal, 2002. 43: p. 83-88. 